\title{
L-Glutamic acid and L-alanine derivatives as building blocks for the synthesis of a chiral monomer precursor of AABB-type polyamide
}

\author{
Romina V. Gómez, Hernán A. Orgueira, and Oscar Varela* \\ CIHIDECAR-CONICET, Departamento de Química Orgánica, Facultad de Ciencias Exactas y \\ Naturales, Universidad de Buenos Aires, Pabellón 2, Ciudad Universitaria, 1428 Buenos Aires, \\ Argentina \\ E-mail: varela@qo.fcen.uba.ar
}

\section{Dedicated to Prof. Roberto Rossi on his $60^{\text {th }}$ birthday and Prof. Edmundo Rúveda on his $70^{\text {th }}$ birthday}

(received 10 Jul 03; accepted 02 Sep 03; published on the web 05 Sep 03)

\begin{abstract}
The chiral monomer $N$-(1'-amino-2'-(S)-propyl)-5-oxo-2-(S)-tetrahydrofurancarboxy-amide hydrochloride (11), a precursor of a AABB-type stereoregular polyamide, has been synthesized from pentachlorophenyl 5-oxo-2-(S)-tetrahydrofurancarboxylate (2) and 2-(S)-amino-1-propanol (3). Compounds $\mathbf{2}$ and $\mathbf{3}$ are derivatives of the natural amino acids L-glutamic acid and L-alanine, respectively. The regioselective attack of the amino group of $\mathbf{3}$ to the ester function of $\mathbf{2}$ led to $\mathrm{N}$ (1'-hydroxy-2'-(S)-propyl)-5-oxo-tetrahydrofurancarboxyamide (4) in 80\% yield. However, the tosylation of the primary hydroxyl group of $\mathbf{4}$, and the subsequent substitution by azide to give $\mathbf{6}$, took place with low yields. Therefore, an alternative route was conducted starting from $\mathbf{3}$, which was selectively $N$-protected as the tert-butyloxycarbonyl derivative ( $N$-Boc), $O$-tosylated and substituted by azide to afford 1-azido-2-(S)- $N$-(tert-butyloxycarbonyl)aminopropane (9) in 41\% yield from 3. The amino group of $\mathbf{9}$ was deprotected by acid hydrolysis and the resulting amine $\mathbf{1 0}$ was regioselectively condensed with $\mathbf{2}$ to give the azide derivative $\mathbf{6}$. Hydrogenolysis of $\mathbf{6}$ afforded the desired monomer $\mathbf{1 1}$ in 69\% yield from $\mathbf{2}$ and $\mathbf{1 0 .}$
\end{abstract}

Keywords: Chiral monomer, stereoregular polyamide, L-alanine, L-alaninol, L-glutamic acid

\section{Introduction}

Common polyamides are a source of environmental pollution as they are resistant to chemical and enzymatic degradation. The highly ordered structures of polyamides, due to strong intramolecular interactions caused by hydrogen bonding, are responsible for their low biodegradability. Such polyamides are based on petroleum, a non-renewable resource, which is 
expected to become difficult to obtain in the near future. One strategy to solve the problems of fossil resources and environment relies upon the utilization of natural regrowing products for the chemical synthesis of polymers. In particular, carbohydrates and amino acids have shown to be highly convenient for the preparation of chiral, biodegradable polymers. ${ }^{1-3}$

The introduction of functionalities and stereocenters in a polymeric chain allows the control of the physical and mechanical properties of the polymer, which usually shows improved biocompatibility and biodegradability. ${ }^{1-4}$ For example, the amide linkages of polyamides formed by sebacic acid and L-phenylalanine itself, or together with L-valine, were cleavable by chymotrypsin. ${ }^{5}$ Also, copolyamides of caprolactam and L-phenylalanine were susceptible to biodegradation. ${ }^{6}$ In our laboratory, we have employed common monosacharides ${ }^{7-9}$ and amino acids ${ }^{10-12}$ for the synthesis of potentially biodegradable, stereoregular polyamides. In particular, the synthesis of stereoregular polyamides of AABB-type is difficult when the monomers derived from carbohydrates or amino acids possesses one or more stereocenters in their structures. ${ }^{1,12,13}$ The requirement for the construction of a stereoregular polymer is the existence of a 2-fold axis of symmetry in the precursor monomer. Otherwise, regioisomerism occurs during the polycondensation leading to a non-stereoregular polyamide with the building blocks radomly oriented along the polymer chain. Therefore, stereocontrol in the polymerization is needed when non-symmetric monomers are employed. ${ }^{11,12,14}$

In the present work we wish to report the synthesis of a monomer precursor of a nonpolypeptidic stereoregular AABB-type polyamide. For the preparation of such a monomer we employed a diacid derived from L-glutamic acid and a diamine derived from L-alanine. The resulting polyamide will possess in both, the diamine and diacid units, a stereocenter having the $S$-configuration. It has been reported ${ }^{1-3}$ that analogous materials could be employed as chiral matrices in asymmetric synthesis.

\section{Results and Discussion}

The diacid derivative $\mathbf{2}$ was prepared by deamination of L-glutamic acid (1) with nitrous acid ${ }^{15}$ followed by activation of the carboxylic acid function with pentachlorophenol. ${ }^{11}$ Compound 2 reacted with L-alaninol (2-(S)-amino-1-propanol, 3), the commercially available product of reduction of L-alanine (Scheme 1). The reaction was highly chemo- and regio-selective to give the single regioisomer $\mathbf{4}$ from the four theoretically possible. Compound $\mathbf{4}$ was obtained crystalline from the reaction mixture in $80 \%$ yield. The high selectivity for the addition through the amino group of $\mathbf{3}$ should be expected as the amine function is a better nucleophile than the alcohol. The higher reactivity of the pentachlorophenyl ester of $\mathbf{2}$ with respect to the lactone group may be attributed to the fact that the pentachlorophenolate is a weaker base (a better leaving group) than the alkoxide, and also because the ester group possesses a hydroxy substituent on the $\alpha$-carbon, which increases the rate of aminolysis. ${ }^{16}$ The structure of $\mathbf{4}$ was confirmed by NMR spectroscopy. Thus, the ${ }^{13} \mathrm{C}$ NMR spectrum of $\mathbf{4}$ showed the signals for the 
amido and lactone carbonyl carbons, the carbon bonded to oxygen (C-1', $65.8 \mathrm{ppm})$ and to nitrogen (C-2', $47.4 \mathrm{ppm}$ ) and the aliphatic carbons (C-3, 4, and C-3'). Furthermore, the low field resonances for C-2 (77.5 ppm) and H-2 (4.86 ppm, in the ${ }^{1} \mathrm{H}$ NMR spectrum of 4) indicated that the lactone ring remained intact, as those signals appear more shielded on opening of the lactone. ${ }^{11,12}$

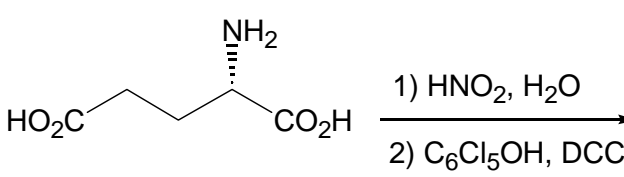

1

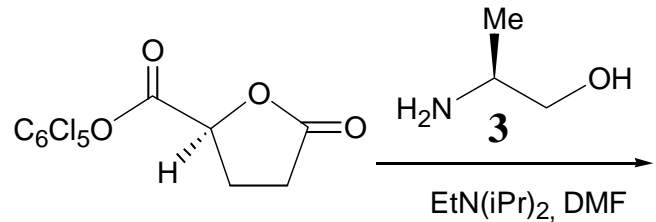

2

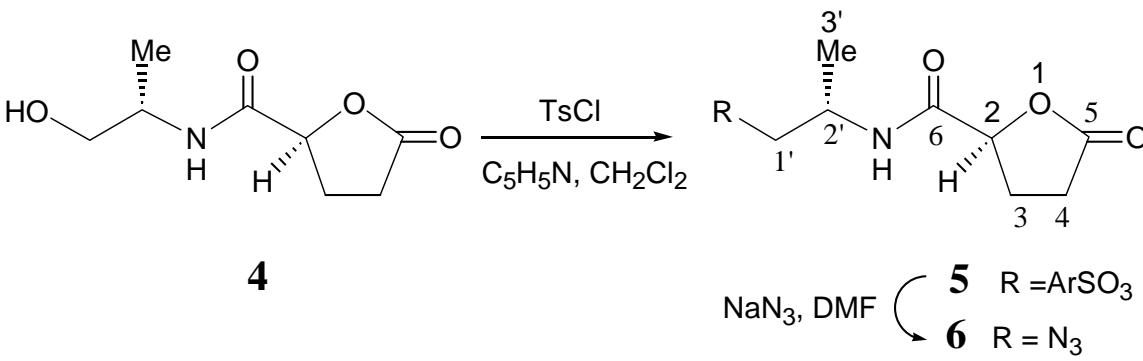

\section{Scheme 1}

To convert the free hydroxyl group of $\mathbf{4}$ into amine, the sequence of sulfonylation and subsequent substitution by azide was followed. The tosylation afforded $\mathbf{5}$ in low yield, under the various reaction conditions employed. A yield somewhat better (34\%) was obtained when the sulfonylation was conducted by a modification of the procedure described by Kabalka et al., ${ }^{17}$ using as solvent dichloromethane containing three molar equivalents of pyridine. However, 5 was also rather unstable to the various conditions employed for the substitution by azide, and decomposition ocurred in all the cases attempted. Therefore, the azide derivative $\mathbf{6}$ was obtained in low yields. Since compound $\mathbf{6}$ is the immediate precursor of the desired "amino acid" 11, an alternative route was designed for the synthesis of $\mathbf{6}$ (Scheme 2) starting from L-alaninol (3). Protection of the amino group of $\mathbf{3}$ with di-tert-butyldicarbonate afforded the $N$-Boc derivative $\mathbf{7}$ (97\% yield). The primary hydroxyl group of 7 was converted into the tosylate $\mathbf{8}$ (70\% yield) by the procedure mentioned above. ${ }^{17}$ The substitution of the sulfonyloxy group by azide was conducted in DMF at $70{ }^{\circ} \mathrm{C}$ for $5 \mathrm{~h}$. The azide derivative $\mathbf{9}$ was isolated as a colorless oil by column chromatography. Finally, the $N$-protecting tert-butyloxycarbonyl group was removed by treatment of 9 with a solution of hydrogen chloride in ethyl acetate. The hydrochoride derivative 10 was obtained in crystalline form (90\% yield). The structures of compounds 7-10 were confirmed by NMR spectroscopy.

The condensation of $\mathbf{2}$ with $\mathbf{1 0}$ was conducted in DMF and in the presence of $N, N$ diisopropylethylamine, which formed the free amino group from the hydrochloride salt 
(Scheme 3). The hydrogenolysis of the azide function of 6 with 10\% Pd/C in hydrochloric acid solution or in hydrogen chloride in methanol led to a low yield of the amine hydrochloride 11, because the lactone ring underwent partial opening by hydrolysis or alcoholysis.

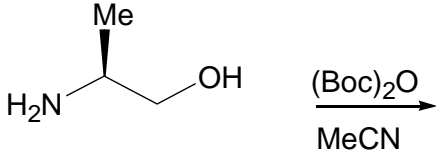

3

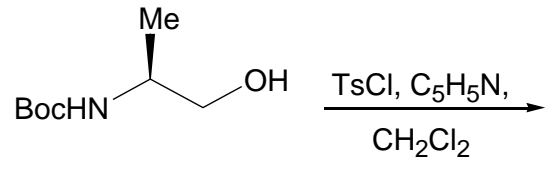

7<smiles>CC(C[OH2+])NC(C)(C)C</smiles>

8<smiles>CCOC(=O)[C@H](Cl)[C@H](C)CN</smiles>

\section{Scheme 2}

However, the hydrogenolysis of the azide group of $\mathbf{6}$ could be conducted without affecting the lactone by using the same catalyst and a 10:1:2 mixture of EtOAc-EtOH-CHCl 3 as solvent. In this way, hydrogen chloride was smoothly generated by hydrogenation of chloroform to give the hydrochloride of the amino group formed in the same reaction. ${ }^{18}$ The hydrochloride derivative $\mathbf{1 1}$ was thus obtained as a crystalline product in 86\% yield. As described for 4, compound 11 exhibited in its ${ }^{13} \mathrm{C}$ NMR spectrum the resonances due to the amide and lactone carbonyl carbons. The low field signals for $\mathrm{C}-2$ (76.9 ppm) and for $\mathrm{H}-2(4.89 \mathrm{ppm})$, in the respective ${ }^{13} \mathrm{C}$ and ${ }^{1} \mathrm{H}$ NMR spectra of $\mathbf{1 1}$ indicated the presence of the lactone ring. Furthermore, the amino acid $\mathbf{1 1}$ gave a satisfactory elemental analysis. The polymerization of $\mathbf{1 1}$ under various reaction conditions is being studied.

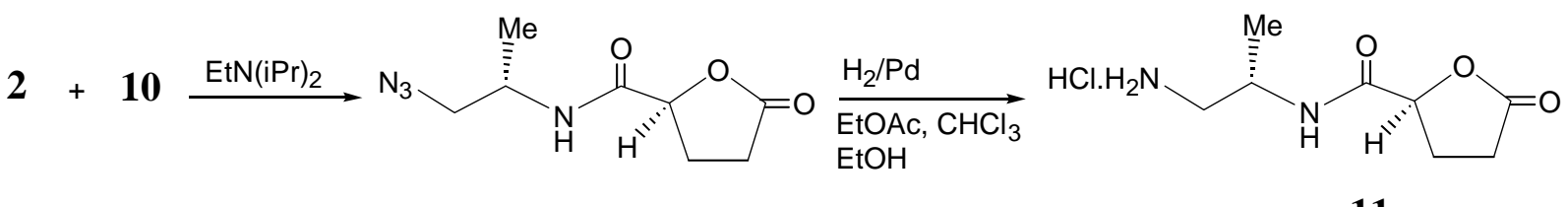

6

11

\section{Scheme 3}

In summary, the synthesis of $\mathbf{1 1}$ was successfully accomplished starting from readily accessible derivatives of L-glutamic acid and L-alanine. The carboxylic acid of $\mathbf{1 1}$ is activated for the homopolycondensation, as lactones readily undergo aminolysis reactions. The polymerization of $\mathbf{1 1}$ will yield a stereoregular AABB-type polyamide having $S$-configuration 
for both stereocenters of the repeating unit.

\section{Experimental Section}

General Procedures. Solvents were dried and purified by appropiate standard procedures. Melting points were determined with a Fisher-Johns apparatus and are uncorrected. Analytical thin layer chromatography (TLC) was performed on $0.2 \mathrm{~mm}$ silica gel $60 \mathrm{~F}_{254}$ (Merck) aluminum supported plates. Detection was effected by exposure to UV light or charring with $5 \% \mathrm{H}_{2} \mathrm{SO}_{4}$ (v/v) in EtOH containing 0.5\% p-anisaldehyde. Column chromatography was performed with silica gel 60 (230-400 mesh, Merck). Optical rotations were measured with a Perkin-Elmer 343 digital polarimeter at $25{ }^{\circ} \mathrm{C}$. Nuclear magnetic resonance (NMR) were recorded on a Brucker AC 200 spectometer at $200 \mathrm{MHz}\left({ }^{1} \mathrm{H}\right)$ and $50.3 \mathrm{MHz}\left({ }^{13} \mathrm{C}\right)$ in $\mathrm{CDCl}_{3}$ solutions (unless otherwise indicated) with TMS as an internal standard.

$N$-(1'-Hydroxy-2'-(S)-propyl)-5-oxo-2-(S)-tetrahydrofurancarboxyamide (4). A solution of pentachlorophenyl 5-oxo-2-(S)-tetrahydrofurancarboxylate ${ }^{11}$ (2, $\left.1.00 \mathrm{~g}, 2.64 \mathrm{mmol}\right)$ in dry DMF $(10 \mathrm{~mL})$ and $N, N$-diisopropylethylamine $(0.4 \mathrm{~mL})$ was cooled to $0{ }^{\circ} \mathrm{C}$, and a solution of 2-(S)amino-1-propanol (L-alaninol, 3, $0.20 \mathrm{~g}, 2.66 \mathrm{mmol})$ in DMF (10 mL) was added dropwise. The mixture was stirred at room temperature for $16 \mathrm{~h}$ and concentrated in vacuum; the residue crystallized from 1:1 EtOAc-hexane. Recrystallization from the same solvent gave chromatographically pure $\left(\mathrm{R}_{f} 0.30\right.$, EtOAc) crystals of $4(0.39 \mathrm{~g}, 80 \%)$; mp 100-102 ${ }^{\circ} \mathrm{C}$; $[\alpha]_{\mathrm{D}}-42$ (c 1.0, $\mathrm{CHCl}_{3}$ ); ${ }^{1} \mathrm{H}$ NMR $\delta 6.75$ (bs, $1 \mathrm{H}, \mathrm{NH}$ ), 4.86 (dd, $1 \mathrm{H}, J=4.5,7.5 \mathrm{~Hz}, \mathrm{H}-2$ ), 4.05 (m, 1H, H-2'), 3.65 (dd, $1 \mathrm{H}, J=4.0,11.2 \mathrm{~Hz}, \mathrm{H}^{\prime} 1^{\prime} \mathrm{a}$ ), 3.51 (dd, $1 \mathrm{H}, J=5.9,11.2 \mathrm{~Hz}, \mathrm{H}-1^{\prime} \mathrm{b}$ ), 3.17 (bs, $1 \mathrm{H}, \mathrm{OH}$ ), 2.66-2.32 (m, 4H, H-3a, 3b, 4a, 4b), 1.15 (d, 3H, $J=6.7 \mathrm{~Hz}, \mathrm{H}-3^{\prime}$ ); ${ }^{13} \mathrm{C}$ NMR $\delta 176.1$, 169.6 (C-5, 6), 77.5 (C-2), 65.8 (C-1'), 47.4 (C-2'), 27.6, 25.7 (C-3, 4), 16.7 (C-3’). Anal. Calcd for $\mathrm{C}_{8} \mathrm{H}_{13} \mathrm{NO}_{4}$ : C, 51.33; H, 7.00; N, 7.48. Found: C, 51.62; H, 6.83; N, 7.56.

$\boldsymbol{N}$-(1'-Azido-2'-(S)-propyl)-5-oxo-2-(S)-tetrahydrofurancarboxyamide (6). To a solution of 4 (0.40 g, $2.14 \mathrm{mmol})$ in anhydrous $\mathrm{CH}_{2} \mathrm{Cl}_{2}(5 \mathrm{~mL})$ and pyridine $(0.5 \mathrm{~mL}, 6.42 \mathrm{mmol})$, cooled to $0{ }^{\circ} \mathrm{C}$, was added tosyl chloride $(0.84 \mathrm{~g}, 4.28 \mathrm{mmol})$ in small portions. The mixture was stirred at room temperature for $20 \mathrm{~h}$, and then diluted with $\mathrm{CH}_{2} \mathrm{Cl}_{2}(50 \mathrm{~mL})$. The solution was washed with saturated aqueous $\mathrm{K}_{2} \mathrm{CO}_{3}$, then with water, and dried $\left(\mathrm{MgSO}_{4}\right)$. Concentration of the organic extract led to 5 (0.22 g, 34\%) as a chromatographically homogeneous syrup $\left(\mathrm{R}_{f} 0.55\right.$, EtOAc); ${ }^{1} \mathrm{H}$ NMR $\delta$ 7.74, 7.30 (2 d, 4H, $J=8.2 \mathrm{~Hz}, \mathrm{H}$-aromatic), 5.23 (bd,1H, $J=8.1 \mathrm{~Hz}, \mathrm{NH}$ ), 4.90 (dd, 1H, $J=4.3,6.9 \mathrm{~Hz}, \mathrm{H}-2$ ), 4.12 (dd, 1H, $J=6.5,11.3 \mathrm{~Hz}, \mathrm{H}-1 \mathrm{a}$ ), 4.05 (d, 1H, $J=4.8,11.3 \mathrm{~Hz}, \mathrm{H}-1 \mathrm{~b}$ ), 3.65 (m, 1H, H-2'), 2.70-2.34 (m, 4H, H-3a, 3b, 4a, 4b), 2.41 (s, 3H, ArCH $), 1.01$ (d, 3H, $J=$ 6.7 Hz, H-3'); ${ }^{13} \mathrm{C}$ NMR $\delta$ 176.2, $169.8(\mathrm{C}-5,6), 143.6,137.8,129.8,126.9$ (C-aromatic), 77.6 (C-2), 67.9 (C-1'), 48.6 (C-2'), 26.7, 25.7 (C-3.4), $21.5\left(\mathrm{ArCH}_{3}\right), 17.7$ (C-3').

Crude compound 5 (0.31 g, $1.02 \mathrm{mmol}$ ) was dissolved in dry DMF (10 mL) and sodium azide ( $0.18 \mathrm{~g}, 2.76 \mathrm{mmol}$ ) was added. The mixture was stirred at $60{ }^{\circ} \mathrm{C}$ for $2 \mathrm{~h}$, then filtered, and the 
fitrate concentrated. The syrup, which showed several spots on TLC (EtOAc), was subjected to column chromatography with mixtures of increasing polarity of hexane-EtOAc (from 2:1 to 1: 4). The colorless syrup that had $\mathrm{R}_{f} 0.50$ was identified as 6 (0.04 g, 21\%); $[\alpha]_{\mathrm{D}}-38$ (c 1.0, $\mathrm{CHCl}_{3}$ ); ${ }^{1} \mathrm{H}$ NMR $\delta 6.45$ (bs, $\left.1 \mathrm{H}, \mathrm{NH}\right), 4.79$ (t, $\left.1 \mathrm{H}, J=7.6 \mathrm{~Hz}, \mathrm{H}-2\right), 4.11$ (m, 1H, H-2'), 3.40 (dd, $1 \mathrm{H}, J=4.9,12.3 \mathrm{~Hz}, \mathrm{H}-1^{\prime} \mathrm{a}$ ), 3.31 (dd, $1 \mathrm{H}, J=5.1,12.3 \mathrm{~Hz}, \mathrm{H}-1^{\prime} \mathrm{b}$ ), 2.63-2.23 (m, 4H, H3a, 3b, 4a, 4b), 1.16 (d, 3H, $J=6.8$ Hz, H-3`); ${ }^{13} \mathrm{C}$ NMR $\delta$ 175.6, 168.8 (C-5, 6), 77.3 (C-2), 55.2 (C-1'), 44.9 (C-2'), 27.6, 25.6 (C-3, 4), 17.8 (C-3'). Anal. Calcd for $\mathrm{C}_{8} \mathrm{H}_{12} \mathrm{~N}_{4} \mathrm{O}_{3}$ : C, 45.28; $\mathrm{H}$, 5.70; N, 26.40. Found: C, 44.73; H, 5.45, N, 26.55.

Alternatively, compound $\mathbf{6}$ was prepared by condensation of $\mathbf{2}$ with the L-alaninol derivative 10. A solution of $2(1.19 \mathrm{~g}, 3.15 \mathrm{mmol})$ in dry DMF $(17 \mathrm{~mL})$ and $N, N$-diisopropylethylamine $(1.12 \mathrm{~mL})$ was cooled to $0{ }^{\circ} \mathrm{C}$ and a solution of $\mathbf{1 0}(0.43 \mathrm{~g}, 3.15 \mathrm{mmol})$ in dry DMF $(17 \mathrm{~mL})$ was added dropwise. The mixture was stirred at room temperature for $16 \mathrm{~h}$ and then the solvent was evaporated under reduced pressure. The residue was purified by column chromatography using mixtures of increasing polarity of hexane-EtOAc (from 9:1 to 1:4). Fractions containing the product having $\mathrm{R}_{f} 0.50$ (EtOAc) were concentrated to give 6 (0.53 g, 80\%). Compound 6 exhibited the same physical and spectral properties as the product described above.

2-(S)-(N-tert-Butyloxycarbonyl)alaninol (7). To a solution of L-alaninol (1.00 g, $13.33 \mathrm{mmol})$ in dry acetonitrile $(40 \mathrm{~mL})$ was added di-tert-butyldicarbonate $(3.00 \mathrm{~g}, 13.77 \mathrm{mmol})$ and triethylamine $(1.86 \mathrm{~mL}, 12.91 \mathrm{mmol})$. The mixture was stirred at room temperature for $24 \mathrm{~h}$, and concentrated. The residue was dried in vacuum to afford 7 (2.25 g, 97\%) as a colorless syrup that crystallized on standing; mp 59-60 ${ }^{\circ} \mathrm{C}$; $[\alpha]_{\mathrm{D}}-10$ (c 1.0; $\mathrm{CHCl}_{3}$ ); ${ }^{1} \mathrm{H}$ NMR $\delta 4.85$ (bs, $1 \mathrm{H}, \mathrm{NH}$ ), 3.68 (m, 1H, H-2), 3.56 (dd, 1H, $J=4.0,10.9 \mathrm{~Hz}, \mathrm{H}-1$ ), 3.43 (dd, $1 \mathrm{H}, J=5.8,10.9 \mathrm{~Hz}, \mathrm{H}-1^{\prime}$ ), 2.55 (bs, 1H, OH), 1.40 (s, 9H, $\left.\left(\mathrm{CH}_{3}\right)_{3}\right), 1.10$ (d, 3H, $\left.J=6.6 \mathrm{~Hz}, \mathrm{H}-3\right) ;{ }^{13} \mathrm{C}$ NMR $\delta 156.4$ $\left(\mathrm{NCO}_{2}\right), 79.8\left(\mathrm{Me}_{3} \mathrm{CO}\right), 67.1(\mathrm{C}-1), 48.6(\mathrm{C}-2), 28.3\left(\left(\mathrm{CH}_{3}\right)_{3} \mathrm{CO}\right), 17.3(\mathrm{C}-3)$. Anal. Cald for $\mathrm{C}_{8} \mathrm{H}_{17} \mathrm{NO}_{3}$ : C, 54.84 ;H, 9.78. Found: C, 54.64; H 9.65.

2-(S)-(N-tert-Butyloxycarbonyl)amino-1-O-p-tosylsulfonyloxypropane (8). A solution of 7 (2.00 g, $11.43 \mathrm{mmol})$ in anhydrous chloroform $(10 \mathrm{~mL})$ and pyridine $(2.70 \mathrm{~mL}, 33.38 \mathrm{mmol})$ was externally cooled with an ice-water bath, and tosyl chloride (3.18 g, $16.71 \mathrm{mmol}$ ) was slowly added. The mixture was stirred at room temperature for $10 \mathrm{~h}$, diluted with $\mathrm{CH}_{2} \mathrm{Cl}_{2}(100 \mathrm{~mL})$ and washed with $5 \%$ aqueous $\mathrm{HCl}$, water, and saturated aqueous $\mathrm{NaHCO}_{3}$. The organic solution was dried $\left(\mathrm{MgSO}_{4}\right)$ and concentrated to afford $8(2.63 \mathrm{~g}, 70 \%)$ as a homogeneous syrup $\left(\mathrm{R}_{f} 0.60,2: 1\right.$ toluene-EtOAc). The product was pure enough for the next step; ${ }^{1} \mathrm{H}$ NMR $\delta 7.80,7.33(2 \mathrm{~d}, 4 \mathrm{H}$, $J=8.3 \mathrm{~Hz}, \mathrm{H}$-aromatic), 4.62 (bs, 1H, NH), 4.07-3.88 (m, 3H, H-1, 1', 2), 2.45 (s, 3, $\mathrm{ArCH}_{3}$ ), 1.15 (d, 3H, H-3); ${ }^{13} \mathrm{C}$ NMR $\delta 154.9\left(\mathrm{NCO}_{2}\right), 144.9,132.7,129.8,128.0$ (C-aromatic), 79.6 ( $\left.\mathrm{Me}_{3} \mathrm{CO}\right), 72.5$ (C-1), $45.3(\mathrm{C}-2), 28.3\left(\left(\mathrm{CH}_{3}\right)_{3} \mathrm{C}\right), 21.6\left(\mathrm{ArCH}_{3}\right), 17.2(\mathrm{C}-3)$.

An analytical sample of $\mathbf{8}$ was obtained by filtration through a short column of silicagel, which was eluted first with toluene to remove some $p$-tolylsulfonyl chloride remaining. The column was eluted with toluene-AcOEt (from 10:1 to 1:1). Evaporation of the fractions containing the product of $\mathrm{R}_{f} 0.60$ (2:1 toluene-EtOAc) afforded solid 8, which recrystallized from EtOAchexane gave mp $64-67{ }^{\circ} \mathrm{C} ;[\alpha]_{\mathrm{D}}-14\left(c\right.$ 1.0, $\mathrm{CHCl}_{3}$ ); and the same spectral data as described 
above. Anal. Calcd for $\mathrm{C}_{15} \mathrm{H}_{23} \mathrm{NO}_{5}$ S. $0.5 \mathrm{H}_{2} \mathrm{O}$ : C, 53.21; H, 7.15; N, 4.14. Found: C, 53.54; H, 6.82; N, 4.50.

1-Azido-2-(S)-(N-tert-butyloxycarbonyl)aminopropane (9). To a solution of crude 8 (2.50 g, $7.60 \mathrm{mmol})$ in dry DMF (20 mL) was added sodium azide (1.48 g, $22.8 \mathrm{mmol})$ and the mixture was heated to $70{ }^{\circ} \mathrm{C}$ for $5 \mathrm{~h}$, with stirring. The resulting suspension was left to reach room temperature and filtered. The solid was washed with $\mathrm{CH}_{2} \mathrm{Cl}_{2}$ and the filtrate was concentrated and extracted with $\mathrm{CH}_{2} \mathrm{Cl}_{2}$. The organic extracts and washing liquids were pooled together and the solvent evaporated to afford a syrup that was subjected to column chromathography (hexaneEtOAc from 99:1 to 95:5). The fractions of the column that contained the product having $\mathrm{R}_{f} 0.60$ (3:1 hexane-EtOAc) were concentrated to give oily $\left.9(0.70 \mathrm{~g}, 60 \%) ;[\alpha]_{\mathrm{D}}-27(c) 1.0, \mathrm{CHCl}_{3}\right) ;{ }^{1} \mathrm{H}$ NMR $\delta 4.56$ (bs, 1H, NH), 3.82 (m, 1H, H-2), 3.41 (dd, 1H, J=4.9, $12.1 \mathrm{~Hz}, \mathrm{H}-1$ ), 3.31 (dd, 1H, $\left.J=4.7,12.1 \mathrm{~Hz}, \mathrm{H}-1^{\prime}\right), 1.45$ (s, 9H, $\left(\left(\mathrm{CH}_{3}\right)_{3} \mathrm{C}\right), 1.18$ (d, 3H, $\left.J=6 \mathrm{~Hz}, \mathrm{H}-3\right) ;{ }^{13} \mathrm{C}$ NMR $\delta 155.1$ $\left(\mathrm{NCO}_{2}\right), 79.7\left(\mathrm{Me}_{3} \mathrm{CO}\right), 56.1$ (C-1), $46.3(\mathrm{C}-2), 28.4\left(\left(\mathrm{CH}_{3}\right)_{3} \mathrm{CO}\right), 17.2(\mathrm{C}-3)$. Anal. Calcd for $\mathrm{C}_{8} \mathrm{H}_{16} \mathrm{~N}_{4} \mathrm{O}_{2}$ : C, 47.99; H, 8.05, N, 27.98. Found: C, 47,57; H, 8.50; N, 28.10.

2-(S)-Amino-1-azidopropane (10). To a solution of $9(0.70 \mathrm{~g}, 3.50 \mathrm{mmol})$ in dry EtOAc $(7.0$ $\mathrm{mL}$ ) was added a saturated solution of hydrogen chloride in EtOAc $(7.0 \mathrm{~mL})$. The mixture was stirred at room temperature for $5 \mathrm{~h}$ and then concentrated. The residue was dissolved in $\mathrm{MeOH}$ (1 mL), the solution was diluted with $\mathrm{CH}_{2} \mathrm{Cl}_{2}(5 \mathrm{~mL})$ and, upon slowly addition of ethyl ether, white crystals of 10 (0.43 g, 90\%) were obtained; mp $45-47{ }^{\circ} \mathrm{C}$; $[\alpha]_{\mathrm{D}}+18$ (c 1.0, DMSO); ${ }^{1} \mathrm{H}$ NMR (DMSO- $\left.d_{6}, 200 \mathrm{MHz}\right) \delta 8.43$ (bs, 3H, $\mathrm{NH}_{3}{ }^{+}$), 3.66 (dd, $1 \mathrm{H}, J=5.4,12.8 \mathrm{~Hz}, \mathrm{H}-1$ ), 3.56 (dd, $1 \mathrm{H}, J=6.1,12.8 \mathrm{~Hz}, \mathrm{H}-1^{\prime}$ ), 3.32 (m, 1H, H-2), 1.21 (d, 3H, $J=6.6 \mathrm{~Hz}, \mathrm{H}-3$ ); ${ }^{13} \mathrm{C}$ NMR $\left(\mathrm{DMSO}-d_{6}, 50.3 \mathrm{MHz}\right) \delta 53.3$ (C-1), 46.3 (C-2), 16.0 (C-3). Anal. Calcd for $\mathrm{C}_{3} \mathrm{H}_{9} \mathrm{~N}_{4} \mathrm{Cl}$ : C, 26.36; H, 6.64; N, 41.03. Found: C, 26.72; H, 7.01; N, 41.36.

$\mathrm{N}$-(1'-Amino-2'(S)-propyl)-5-oxo-2-(S)-tetrahydrofurancarboxyamide hydrochloride (11). Compound 6 (0.50 g, $2.36 \mathrm{mmol})$ dissolved in 10:1:2 EtOAc-EtOH-CHCl 3 (15 mL) was hydrogenated in the presence of $10 \% \mathrm{Pd} / \mathrm{C}(70 \mathrm{mg})$ at room temperature and under pressure (45 psi). After $4 \mathrm{~h}$ the mixture was filtered and the catalyst was washed with methanol. The filtrate and the washing liquids were pooled and concentrated to give a syrup that was dissolved in anhydrous methanol. Dropwise addition of dry ethyl ether afforded crystalline 11 (0.45 g, 86\%); mp 169-171 ${ }^{\circ} \mathrm{C},[\alpha]_{\mathrm{D}}+40$ (c 1.0, DMSO); ${ }^{1} \mathrm{H}$ NMR (DMSO-d, $\left.200 \mathrm{MHz}\right) \delta 8.43$ (d, $1 \mathrm{H}, J=8.0$ $\mathrm{Hz}, \mathrm{CONH}$ ), 8.19 (bs, 3H, $\mathrm{NH}_{3}^{+}$), 4.89 (dd, 1H, $J=5.5,7.7 \mathrm{~Hz}, \mathrm{H}-2$ ), 4.06 (m, 1H, $J=6.7 \mathrm{~Hz}$, H-2'), 2.86 (d, 2H, $J=6.7$ Hz, H-1'), 2.55-2.15 (m, 4H, H-3a, 3b, 4a, 4b), 1.13 (d, 3H, $J=6.7$ $\mathrm{Hz}, \mathrm{H}-3^{\prime}$ ); ${ }^{13} \mathrm{C}$ NMR (DMSO-d, $\left.50.3 \mathrm{MHz}\right) \delta$ 176.9, 169.3 (C-5, 6), 76.9 (C-2), 42.8 (C-1', 2'), 27.1, 25.3 (C-3, 4), 17.8 (C-3'). Anal. Calcd for $\mathrm{C}_{8} \mathrm{H}_{14} \mathrm{~N}_{2} \mathrm{O}_{3} \mathrm{Cl}$ : C, 43.15; H, 6.79; N, 12.58. Found: C, 43.11; H, 6.82; N, 12.45.

\section{Acknowledgments}

Financial support from the University of Buenos Aires (Project X108) and from the National 
Research Council of República Argentina (CONICET) is gratefully acknowledged. O.V. is a research Member of CONICET and R.V.G. is a Research Fellow from the same Institution.

\section{References}

1. Varela, O.; Orgueira, H. A. Adv. Carbohydr. Chem. Biochem. 1999, 55, 137.

2. Okada, M. Prog. Polym. Sci. 2002, 27, 87.

3. Thiem, J.; Bachmann, F. Trends Polym. Sci. 1994, 2, 425.

4. Gonsalves, K. E.; Mungara, P. M. Trends Polym. Sci. 1996, 4, 25.

5. Bianco, B.; Castaldo, L.; del Gaudio, A.; Maglio, G.; Palumbo, R.; La Cara, F.; Peluso, G.; Petillo, O. Polym. Bull. 1997, 39, 279.

6. Demicheli, A.; Russo, S.; Mariani A. Polymer 2000, 41, 1481.

7. Bueno, M.; Zamora, F.; Molina, I.; Orgueira, H. A.; Varela, O.; Galbis J. A. J. Polym. Sci., Part A: Polym. Chem. 1997, 35, 3645.

8. Romero Zaliz, C. L.; Varela, O. J. Carbohydr. Chem. 2001, 20, 689.

9. Orgueira, H. A.; Varela, O. J. Polym. Sci.:Part A, Polym. Chem. 2001, 39, 1024.

10. Orgueira, H. A.; Bueno, M.; Funes, J. L.; Galbis J. A.; Varela, O. J. Polym. Sci.:Part A, Polym. Chem. 1998, 36, 2741.

11. Orgueira, H. A.; Varela, O. Tetrahedron:Asymmetry 1997, 8, 1383.

12. Orgueira, H. A.; Erra- Balsells, R.; Nonami, H.; Varela, O. Macromolecules 2001, 34, 687.

13. Regaño, C.; Martinez de Ilarduya, A.; Iribarren, I.; Rodriguez-Galán, A.; Galbis, J. A.; Muñoz Guerra, S. Macromolecules 1996, 29, 8404.

14. Chen, L.; Kiely, D. E. J. Org. Chem. 1996, 61, 5847.

15. Ravid, U.; Silverstein, R. M.; Smith, L. R. Tetrahedron 1978, 34, 1449.

16. Ogata, N.; Sanui, K.; Ohtake, T.; Nakamura, H. Polym. J. 1979, 11, 827.

17. Kabalka, G. W.; Varma, M.; Varma, R. S. J. Org. Chem. 1986, 51, 2386.

18. Secrist III, J. A.; Logue, A. M. W. J. Org. Chem. 1972, 37, 335. 